\title{
OS EFEITOS DA ATIVIDADE TURÍSTICA NO LITORAL NORTE DO RIO GRANDE DO SUL ${ }^{1}$
}

\author{
Elmer Agostinho Carlos de Matos ${ }^{2}$ \\ Nelson Luís Sambaqui Gruber ${ }^{3}$
}

\section{Resumo}

O litoral de vários países do mundo tem sido a área mais densamente ocupada e a que mais atrai um número elevado de turistas. O litoral norte do Rio Grande do Sul foi, a partir da década de 60, uma área em que a exploração turística desempenhou um papel importante na formação dos assentamentos urbanos existentes. Esse processo de urbanização, que ocorreu sobre um ambiente natural frágil, tem provocado vários problemas ambientais tais como a destruição das dunas, banhados, balneários, campos, terras úmidas e vegetação natural. Também se destaca a maior pressão sobre as poucas infra-estruturas de saneamento existente.

Palavras chaves: Turismo, urbanização, problemas ambientais, zona costeira

\begin{abstract}
The coast of several countries of the world has been the area more densely busy and the one that more attracts a high number of tourists. The north coast of Rio Grande do Sul was, starting from the decade of 60 , an area in that the tourist exploration played an important part in the formation of the existent urban establishments. That urbanization process, which happened on a fragile natural environment, has been provoking several environmental problems such as the destruction of the dunes, swamps, spas, fields, humid lands and natural vegetation. They also stand out the largest pressure on the few infrastructures of existent sanitation.
\end{abstract}

Key words: Tourism, urbanization, environmental problems, coastal area

\section{Introdução}

\footnotetext{
${ }^{1}$ Ensaio final desenvolvido na disciplina de Gestão e Gerenciamento da Zona Costeira

${ }^{2}$ Mestrando em Geografia, na área de Análise Territorial no Instituto de Geociências da Universidade Federal do Rio Grande do Sul. email: elmermats@yahoo.com.br.É bolsista do CNPq.

${ }^{3}$ Docente da disciplina de Gestão e Gerenciamento da Zona Costeira no Departamento de Geografia da UFRGS. nelson.gruber@ufrgs.br.
} 
A zona costeira é, ao nível mundial, a que mais população concentra. Castro A. e Morales C. (2006), citando PNUMA (1992), indicavam que 60\% da população mundial se concentrava na zona costeira e, se calcula que em 2100 , esta concentrará cerca de $75 \%$. Os autores destacam a escassez do espaço, a existência de recursos naturais, o bom clima, a fertilidade do solo, a convergência de vários usos e atividades, o valor paisagístico e a concentração de assentamentos humanos como sendo as razões principais dessa atração.

A zona costeira brasileira, com aproximadamente 388 mil km2 e com uma extensão de $8698 \mathrm{~km}$, alberga cerca de $25 \%$ da população, residente em cerca de 400 municípios, dos quais 13 dos 17 são capitais de estados litorâneos (NAKANO, 2006). Esta é uma área fortemente ocupada, apresentando as maiores densidades populacionais, sendo, em média, 5 vezes maior que a média nacional (IDEM).

De acordo com Nakano (2006), foi com a chegada dos europeus em busca de recursos naturais, que a costa brasileira começou a ser ocupada com os assentamentos humanos urbanos. A partir dessa época até ao final do século XIX, apenas três cidades concentravam a maior parte da população brasileira, nomeadamente Rio de Janeiro, Salvador e Recife. A ocupação da zona costeira brasileira começou a ser problemática a partir de 1950, quando se inicia o processo de industrialização, dando origem ao processo de metropolização. Daí, começou-se a observar na costa marítima brasileira, uma proliferação de várias metrópoles e cidades médias e pequenas, concentrando grande parte de população e de diversas atividades.

Dada as condições oferecidas pela zona costeira, como foram referidas por Castro A. e Morales C. (2006), esta zona, para além de concentrar grandes contingentes humanos, concentra também várias atividades, das quais se destaca o turismo.

A atividade turística apenas adquiriu grande expressão no mundo depois da segunda metade do século XX. Atualmente, o turismo é uma das principais atividades que utiliza o litoral, estando, muitas vezes, associado aos gravíssimos problemas de ocupação da orla, refletindo-se nos problemas de ordenamento do território (e de ocupação de áreas de risco), sendo, também, fonte de agravamento de conflitos latentes de interesses na zona costeira (CNADS, 2001).

O presente ensaio pretende discutir a relação turismo versus ocupação da orla no litoral norte do Rio Grande do Sul, com especial enfoque para o litoral dos municípios de Xangri-lá, Capão da Canoa e Arroio do Sal. Ao longo do ensaio, tentar-se-á abordar sobre o turismo de segunda residência e o de veraneio. Seu impacto sobre as infra-estruturas existentes, principalmente nos meses de verão, onde a avalanche de turistas que se desloca para esta área aumenta significativamente e sobre o meio ambiente. 
A informação constante no ensaio é fruto de leituras feitas sobre o turismo e suas implicações no meio natural e, as caraterísticas da zona costeira do litoral norte do RS. Também se recorreu à visita de campo efetuada nos dias 18 e 19 de Maio de 2009 ao litoral norte do RS, para sustentar alguns aspectos abordados ao longo do texto.

\section{Ocupação da zona costeira pelo homem}

A ocupação dos homens na zona costeira não é recente, ela é muito antiga, pois por volta do IV milênio antes de cristo, já se construíam diques no delta do Nilo. Foram vários os povos que se localizaram na zona costeira e dele desenvolveram as suas atividades de subsistência, principalmente a pesca.

Ao longo da história do homem, observou-se que o litoral teve um papel muito importante na formação dos povos e culturas. O litoral concentrou o tráfico comercial, ainda mesmo na idade do bronze. Foi nele, onde se desenvolveram fortalezas e importantes assentamentos humanos, como a de Troia. Na idade do ferro, o litoral é, sobretudo, um meio de progressão, onde os gregos e fenícios dominaram o comércio e a economia no mediterrâneo (CASTRO A. e MORALES C., 2006).

No domínio da atividade comercial, que utilizava principalmente a zona costeira e os estuários, várias potências utilizaram as inovações disponíveis na altura e passaram a ampliar a atividade comercial para outras regiões. Nesse cenário, destacam-se os portugueses e espanhóis e mais tarde os ingleses e franceses que passaram a dominar o comércio mundial. Esse domínio também se manifestou na dominação de diferentes povos e culturas. Uma das estratégias de domínio era a ocupação do litoral e daí o seu progresso para o interior, com a finalidade de encontrar outros recursos naturais importantes ao comércio desenvolvido na altura.

A ocupação, fixação e exploração da zona costeira está relacionada a vários fatores, sendo uns são de caráter zonal (referente a sua localização), outros de caráter histórico e tradicional e outros ainda relacionados ao desenvolvimento das técnicas (CASTRO A. e MORALES C., 2006).

No Brasil, a ocupação da zona costeira esteve relacionada com a chegada dos primeiros europeus em busca das riquezas naturais existentes. Até 1950 a ocupação dessa zona não se afigurava como problemática, pois o país não era industrializado e o padrão de ocupação do litoral encontrava-se ainda numa fase embrionária. A partir de 1950, observa-se uma intensificação de atividades ligadas ao processo de industrialização, acentuada com a chegada das multinacionais. Nesse período, observa-se uma explosão urbana, originando o 
processo de metropolização. As cidades crescem verticalmente e horizontalmente, ocupando, em alguns casos, áreas de vulnerabilidade ambiental (NAKANO, 2006).

Moraes (1999) citado por Strohaecker (2006) refere que a intensificação da ocupação do litoral nas últimas décadas é reflexo da urbanização, industrialização e exploração turística. Desse conjunto de fatores, a urbanização e a exploração turística foram os principais responsáveis pela ocupação do litoral norte do RS (STROHAECKER ET AL, 2006).

Até 1965 haviam no litoral norte do RS apenas 3 municípios, nomeadamente Osório, Santo Antônio da Patrulha e Torres. E, apenas perto de $25 \%$ da população era urbana, destacando-se o município de Osório que tinha $28 \%$ da sua população classificada como urbana (STROHAECKER ET AL, 2006). Os processos emancipatórios e os investimentos públicos e privados fizeram com que em 1980, 15 anos depois, a população urbana do litoral norte duplicasse $(54,37 \%)$, e Tramandaí, o mais recente município, desmembrado de Osório, se tornasse no município completamente urbano (93,34\%) (STROHAECKER ET AL, 2006).

Até a promulgação da Constituição Federal de 1988, a criação de novos municípios se regia por legislação pouco flexível, fator que explica o reduzido número de municípios no litoral norte do RS. Nos princípios da década de 1980 apenas foram criados 2 municípios, desmembrados de Osório, dentre os quais o município de Capão da Canoa. Após a constituição, o número de municípios explodiu, atingindo os atuais 21. Em 1988, desmembrando-se de Torres, forma-se o município de Arroio do Sal e, em 1992 forma-se o município de Xangri-lá, que se desmembrou do município de Capão da Canoa (STROHAECKER ET AL, 2006).

Em 1991 a proporção da população urbana do litoral norte do RS aproximou-se dos $70 \%(69,02 \%)$ e, os municípios de Arroio do Sal e Capão da Canoa tornaram-se completamente urbanos, com 94,36\% e 99,22\%, respectivamente (STROHAECKER ET AL, 2006).

\section{Definição e características da zona costeira}

A zona costeira é o lugar de contato entre a terra e o mar, onde a água doce se mistura com a água salgada, gerando uma zona de transição onde atuam distintos elementos. Castro A. e Morales C. (2006) referem que, num sentido amplo, a zona costeira é definida como a terra firme que é influenciada pela proximidade do mar e a parte do mar afetada pela proximidade da terra, isto é, é a área na qual os processos que dependem da interação marterra são mais intensos. Em geral, esta área abrange os recursos terrestres e marinhos (tanto 
renováveis como não renováveis), as praias, terrenos superficiais e submersos, a plataforma continental e as águas territoriais.

A zona costeira brasileira é definida pela Lei 7.661, como sendo "o espaço geográfico de interação do ar, do mar e da terra, incluindo seus recursos renováveis ou não, abrangendo uma faixa marítima e outra terrestre" (PROJETO ORLA, 2002).

A nível internacional existem diferentes definições para a zona costeira, contudo, predominam duas concepções para a sua definição, sendo uma com viés naturalista, adotada na maior parte dos trabalhos acadêmicos e a outra adotada nos trabalhos governamentais de planejamento da zona costeira, com um viés político-administrativo.

Segundo o projeto Orla (2002), a concepção naturalista concebe este espaço como uma unidade natural, passível de ser delimitada no terreno por aspectos físicos ou biológicos. A concepção administrativa compreende a zona costeira como sendo uma unidade políticoadministrativa, e que não necessariamente se apresenta com os limites naturais bem compreensíveis.

No Brasil, depois de tentativas do uso do método naturalista para a definição da zona costeira para o seu planejamento, este mostrou-se pouco ajustado a realidade. Neste contexto, adotou-se a concepção político-administrativa. Disso, resultou o seguinte: na faixa marítima, considera-se todo o mar territorial, sendo o limite deste delimitado pela Convenção das Nações Unidas sobre o Direito do Mar, que confere o limite máximo de extensão de 12 milhas náuticas, contadas a partir da linha de base da $\operatorname{costa}^{4}$; na faixa terrestre, recorreu-se aos limites de fronteira interior dos municípios considerados costeiros (PROJETO ORLA, 2002).

Ao longo da abordagem que será desenvolvida no ensaio, recorrer-se-á, com alguma frequência, a uma subunidade da zona costeira que é a orla marítima. Esta, segundo o projeto Orla (2000), é definida como sendo uma unidade geográfica inclusa na zona costeira, delimitada pela faixa de interface entre a terra firme e o mar. Os limites estabelecidos para a orla marítima são os seguintes: na faixa marítima o seu limite é a isóbata de 10 metros (assinaladas em todas as cartas náuticas), profundidade na qual a ação das ondas passa a sofrer a influência da variabilidade topográfica do fundo marinho, promovendo o transporte de sedimentos. Para a faixa terrestre o limite varia de acordo com o tipo de assentamento humano, sendo 50 metros para as áreas urbanizadas e 200 metros para as áreas não

\footnotetext{
${ }^{4}$ A Linha de base da costa é definida como "origem de medida da largura do mar territorial e das demais áreas marítimas sob jurisdição nacional (zona contígua, zona exclusiva econômica e plataforma continental). No geral, é linha de baixa mar do litoral brasileiro, tal como indicada nas cartas náuticas de grande escala. Nos locais em que a costa apresenta recortes profundos e reentrâncias ou em que existe uma franja de ilhas ao longo da costa na sua proximidade imediata, adota-se o método de linhas de base reta, ligando pontos apropriados, estabelecidos pelo Decreto 1.290 de 21/10/1994" (PROJECTO ORLA, 2002)
} 
urbanizadas. A delimitação dessa largura é feita em função da linha de preamar ou do limite final de ecossistema existente na área (que podem ser feições de praias, dunas, áreas de escarpa, costões rochosos, falésias, restingas, manguezais, marismas, lagunas, estuários, canais ou braços de mares).

\section{Características da zona costeira do litoral norte do Rio Grande do Sul}

Segundo Tomazelli e Villwock (2000), o litoral do estado do Rio Grande do Sul, estende-se desde Torres (a norte do estado) até a desembocadura do Arroio do Chuí (no sul do estado), constituindo-se na mais extensa planície costeira do território brasileiro, cobrindo uma área de cerca de 33 mil km2, chegando, em alguns casos, a ter uma largura superior a $100 \mathrm{~km}$.

Almeida et al (2006) refere que a plataforma continental desta costa é larga, com uma extensão que varia dos 150 a $200 \mathrm{~km}$, com profundidade máxima que varia de 100 a 140 metros e com um declive suave da ordem dos 0,5 a $1,5 \mathrm{~m} / \mathrm{km}$. A antepraia é caracterizada por ser rasa e extensa, com limite externo entre as profundidades de 10 a 15 metros, e constituída por depósitos arenosos.

O litoral gaúcho se divide em 3 partes, nomeadamente o litoral norte, médio e sul. O litoral norte, com uma extensão de $618 \mathrm{~km}$, devido a sua idade geológica recente (cerca de 5000 a.C.), apresenta ecossistemas frágeis e raros (FEPAM, 2000). Esta faixa do litoral engloba 21 municípios, começando do município de Torres (a norte) até Palmares do Sul (fazendo fronteira com o litoral médio), vide figura 1.

De Tramandaí até o limite norte do estado, a planície costeira é estreita e tem o seu limite interno marcado pelas escarpas da Serra Geral, borda leste da bacia do Paraná, chegando até a linha de costa atual, em Torres, formando ali o único promontório rochoso deste trecho da costa (VILLWOCK, 1994). Segundo a FEPAM (2000), após a zona de interface com o mar, identifica-se a típica planície sedimentar costeira (composta por dunas primárias, secundárias e terciárias), depois segue-se o cordão de lagoas litorâneas e chegando até a encosta da serra, formada pelos rios Maquiné e Três forquilhas. Ainda segundo a mesma fonte, esta área localiza-se sobre a área de reserva da biosfera da Mata Atlântica, cuja zona núcleo consiste em uma área de preservação permanente de interesse nacional.

Figura 1: Localização dos municípios do litoral norte do RS 


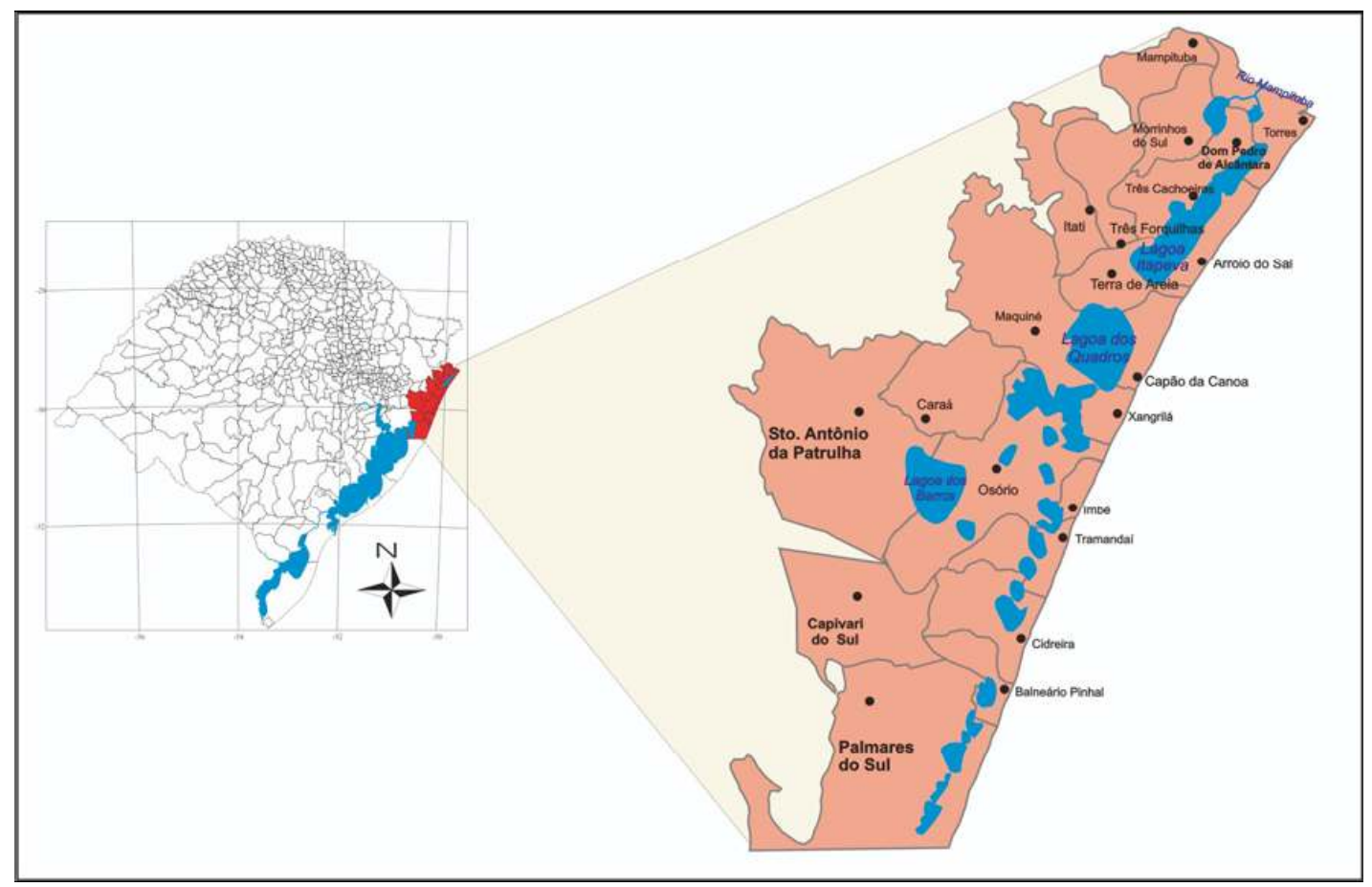

Fonte: Fujimoto (2006)

O litoral é caracterizado por apresentar uma costa retilínea, com orientação NE-SW a frente de sucessões de cordões litorâneos, regionalmente denominados por barreiras, estando, em muitos pontos, recobertos por extensos campos de dunas os quais progradam sobre banhados e um conjunto de lagoas e lagunas costeiras (TOMAZELLI e VILLWOCK, 2000 e CALLIARI ET AL, 2006).

Segundo a FEPAM (2000), esta região se encontra sob influência do clima tropical úmido costeiro e apresenta solos de fertilidade natural baixa e de alta susceptibilidade a ação eólica.

Em termos morfológicos, a linha da costa é caracterizada por ser essencialmente uma praia arenosa baixa (TOMAZELLI e VILLWOCK, 2000). Almeida et al (2006) citando Nicolodi et al (2002) e Gruber (2002), referem que os sedimentos praiais são constituídos principalmente de areia fina bem selecionada (com tamanho médio de 0,2 $\mathrm{mm}$ ).

As praias ao longo da costa são totalmente expostas, com exceção de Torres onde as formações rochosas constituídas por arenitos, basaltos e sequências vulcano-clásticas conferem um pequeno grau de proteção da dinâmica costeira (CALLIARI ET AL, 2006).

Segundo Calliari et al (2002), citando estudos realizados por Tomazelli e Villwock (1992), Toldo Jr. et al (1993) e Weschenfelder (1996), referem que no litoral norte predominam praias intermediárias a dissipativas e é caraterizado por apresentar dunas frontais bem desenvolvidas. 


\section{Atividade turística}

O turismo é uma das atividades mais relevantes ao nível local, regional e nacional, contudo apresenta impactos negativos e de natureza cumulativa nos ambientes costeiros (VELOSO GOMES e TEVEIRA-PINTO, 1997, citados por CNADC, 2001). Ao se adotar o turismo como um setor de desenvolvimento de uma localidade é importante que se desenvolva de uma forma sustentável, minimizando-se os impactos negativos e maximizando-

se os positivos. É, também importante, que este tome em conta as comunidades locais, que não devem ser excluídas desse benefício, pois, na maioria dos casos, os benefícios são "privatizados" e o malefícios são "socializados".

O Organização Mundial do Turismo (OMT) entende que o turismo sustentável é aquele em que se realiza a gestão de todos os recursos de tal forma que as necessidades econômicas e estéticas possam ser satisfeitas, mantendo-se ao mesmo tempo a integridade cultural, os processos ecológicos essenciais, a diversidade e o sistema de suporte a vida (VASCONCELOS e CORIOLANO, 2008).

O turismo tem impactos positivos e negativos, porém, a vertente positiva é várias vezes utilizada como suporte para a aprovação de determinados empreendimentos turísticos e, como publicidade das alterações econômicas positivas e ainda como cartão de visita. Nesse âmbito, essa vertente esconde os impactos negativos.

Neste ensaio, privilegiar-se-á a análise dos impactos negativos como uma das formas de mostrar o outro lado da moeda, pouco ilustrado, principalmente pelos representantes públicos.

Das várias atividades que podem ter um impacto negativo sobre o ambiente costeiro, o turismo é uma delas. A CNADS (2001), citando Middleton e Sieber (1999), revela que as principais pressões exercidas pelo turismo na zona costeira são: a) desenvolvimento e urbanização em ambientes naturais; b) poluição da água do mar e da praia; c) perda da biodiversidade, que pode ser resultante da erosão das dunas e de outros ecossistemas costeiros devido a construções e pressões das atividades dos visitantes; d) excesso de uso de água potável diretamente para os alojamentos turísticos e, indiretamente para outras atividades ligadas ao turismo, como a rega dos campos de golfe, jardins, e outros; e) congestão do tráfico automóvel, ruído, perda de qualidade do ar associado ao elevado consumo/uso do automóvel privado; f) tratamento e descarga de águas residuais inadequadas e; g) a decadência urbana de vários locais que registram uma grande afluência turística. 
As características das praias do litoral norte não são das melhores (em termos de paisagem turística) se comparada com as do sudeste e norte do Brasil. Este fato não impede que o litoral se torne num destino turístico preferencial da população gaúcha. Nos meses de verão, Janeiro e Fevereiro (principalmente), o litoral é invadido por um número considerável de visitantes que vêm desfrutar do ambiente costeiro. Para além dessa invasão temporária, a construção de segunda residência nesta faixa adquiri cada vez mais expressão, sendo áreas onde são construídos condomínios fechados e luxuosos e, por vezes, com implicação não só no ambiente costeiro como também na privatização do acesso a porções da praia.

A urbanização dos municípios do litoral norte do RS foi, em muitos deles, devido a exploração turística sazonal. O "fenómeno veraneio" e a construção de segunda residência, principalmente nos municípios de Arroio do Sal, Capão da Canoa e Xangri-lá mostram o seu impacto no desenvolvimento dos assentamentos urbanos. A possibilidade de desfrute de um ambiente costeiro terá contribuído bastante para a urbanização dos municípios e para o surgimento da especulação imobiliária.

Os cidadãos com posse foram comprando quase todos os lotes existentes na orla ou próximo dela, construindo habitações e condomínios fechados para indivíduos/grupo de pessoas com poder aquisitivo (vide foto 1). Isto se reflete no tipo de habitação existente na faixa costeira, que são "verdadeiras" mansões e, que de certa forma, pronunciam cada vez mais as grandes desigualdades entre os que têm e as comunidades locais que vivem em habitações precárias.

Foto 1: Construcões de habitacões e um condominio fechado

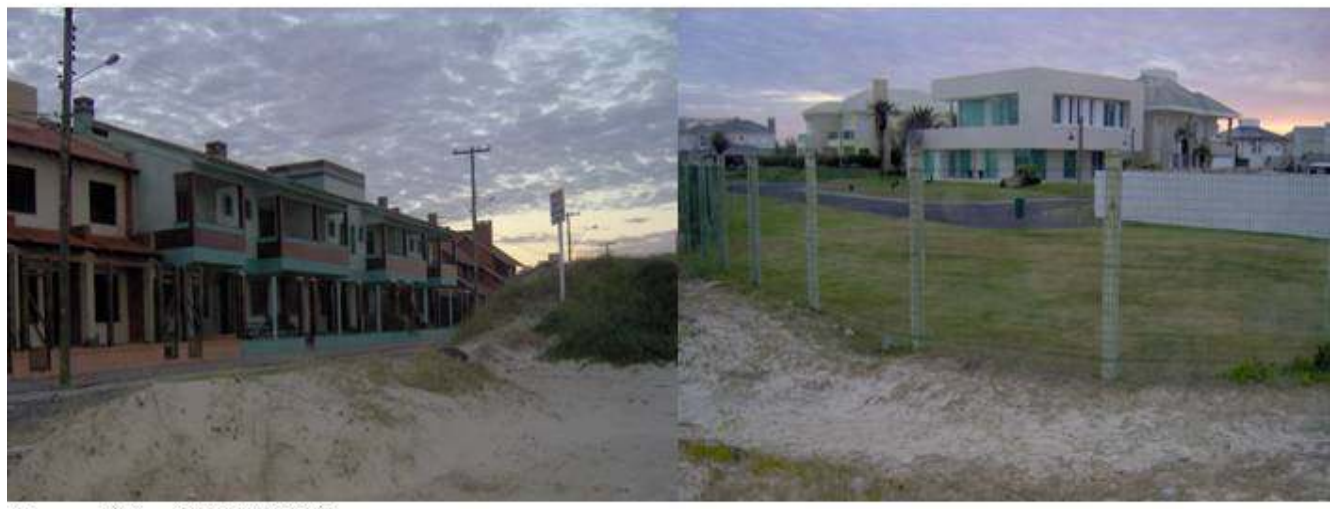

Fonte: Cristo (18/05/2009)

Boa parte dessas habitações é construída em áreas de ecossistemas frágeis, como as dunas. Várias lagunas são soterradas para poder dar espaço a construção de habitações ou condomínios fechados. Esta ação está a contribuir para a perda de biodiversidade e da destruição do ecossistema (que por si só já é frágil e raro), com maior enfoque para a 
destruição das dunas. Um estudo desenvolvido por Fujimoto et al (2006) refere que dentre os principais problemas ambientais que ocorrem no litoral norte de RS, destacam-se: aterramento de banhados para a construção civil; ocupação das áreas de banhados por moradias irregulares; ocupação das margens da lagoa dos Quadros por loteamentos e condomínios fechados, impedindo o acesso ao patrimônio público; retirada de areia das dunas para aterros na construção civil; destruição da vegetação pioneira das dunas e dos sambaquis; comprometimento da balneabilidade das praias; alteração dos costumes da população local nos meses de verão; entre outros.

Observando a tabela 1, fica bem evidente o impacto do turismo nos meses de verão, onde o aumento da população dos municípios é 10 vezes superior a população fixa estimada pelo IBGE para o ano de 2007. Nesses meses a densidade populacional aumenta consideravelmente. É importante referir que a densidade demográfica nesses meses está subestimada pelo fato da população concentrar-se principalmente na faixa do litoral, isto é, bem próximo da praia propriamente dita, daí a área ocupada pelos turistas reduz.

Tabela 1: População fixa e população flutuante (nos meses de verão)

\begin{tabular}{|l||r||r||r|}
\hline & Arroio do Sal & Capão da Canoa & Xangri-lá \\
\hline \hline População (2007) & 6635 & 37405 & 10602 \\
\hline Área (km2) & 121 & 97 & 61 \\
\hline \hline Densidade pop 2007 & 55 & 386 & 174 \\
\hline População flutuante & 80000 & - & 100000 \\
\hline Dens. Pop. flutuante & 661 & - & 1639 \\
\hline
\end{tabular}

Fonte: IBGE, 2007 e site dos respectivos municípios

Tabela 2: Evolução da ocupação de domicílio nos 3 municípios de referência (19912000)

\begin{tabular}{|c|c|c|c|c|}
\hline \multirow{2}{*}{ Municípios } & \multicolumn{2}{|c|}{1991} & \multicolumn{2}{|c|}{2000} \\
\hline & $\begin{array}{c}\mathrm{N}^{\mathrm{o}} \text { de } \\
\text { domicílios }\end{array}$ & $\begin{array}{c}\text { \% de domicílios } \\
\text { ocupados }\end{array}$ & $\begin{array}{c}\mathrm{N}^{\mathrm{o}} \text { de } \\
\text { domicílios }\end{array}$ & $\begin{array}{c}\text { \% de domicílios } \\
\text { ocupados }\end{array}$ \\
\hline Arroio do Sal & 5.149 & 16,74 & 8.836 & 18,79 \\
\hline Capão da Canoa & 26.834 & 24,46 & 28.889 & 30,93 \\
\hline Xangri-lá & - & - & 11.721 & 19,96 \\
\hline
\end{tabular}

Fonte: STROHAECKER et al, 2006

Relacionando a tabela 1 e 2 pode-se perceber a importância do "fenómeno veraneio" na produção do espaço urbano dos municípios. A porcentagem dos domicílios ocupados nos 3 municípios de referência é inferior a 31\% na maior parte do ano, sendo apenas totalmente ocupadas na época do veraneio. Esta forma de produção do espaço urbano, que torna os 
municípios despovoados em grande parte do ano e, em poucos meses, densamente ocupados, cria pressão nas infra-estruturas urbanas existentes, que na maioria das vezes não são planejadas para atender a demanda veraneia.

A concentração de população nesses meses implica um aumento do consumo de água, de energia e a produção de dejetos de lixo de diversos tipos. Boa parte dos municípios do litoral norte gaúcho não apresenta ou têm poucas infra-estruturas para atender esta enorme demanda turística, daí que isso pode ter impactos negativos na saúde pública, na poluição das águas do mar e da praia. Isto é confirmado pelo estudo realizado por Fujimoto et al (2006) que evidencia a necessidade de se efetuar grandes investimentos na área de saneamento (abastecimento de água e esgoto), porque podem comprometer a qualidade ambiental.

O processo de ocupação do litoral norte do RS parece não acompanhar com o crescimento de infra-estruturas de saneamento necessárias para garantir a qualidade de vida desejável. Em todos os municípios constata-se que a situação do abastecimento de esgoto (rede geral ou pluvial) é deveras preocupante. Isso também é observado nos 3 municípios em estudo (FUJIMOTO ET AL, 2006). As preocupações aumentam quando se sabe que, em todos os municípios do litoral norte do RS, pouco mais de 35\% do destino do esgoto ocorre a céu aberto. Para os municípios de Arroio do Sal e Xangri-lá a situação é mais grave, com $75,85 \%$ e 51,88\% respectivamente. Para o município de Capão da canoa, as cifras porcentuais são de 10,56\% (FUJIMOTO ET AL, 2006).

Em relação ao abastecimento de água a situação é também preocupante, apesar de 64,28\% dos domicílios estarem ligados a rede geral. Em Capão da Canoa, Xangri-lá e mais 5 municípios a situação apresentar-se como menos preocupante, pois mais de $79 \%$ dos domicílios estão ligados a rede geral. Para os restantes a situação é diferente, o poço ou a nascente apresentam-se como principal fonte de abastecimento de água. Para Arroio do Sal essa proporção aproxima-se dos 70\% (FUJIMOTO ET AL, 2006).

Dada a enorme concentração de população em apenas poucos meses, observa-se também que durante esse período, o uso do automóvel privado aumenta drasticamente. Isso provoca o congestionamento do tráfego automóvel, sendo difícil a transição nas ruas pelos pedestres, pois os automóveis apropriam-se, não só das ruas, como também da praia.

As implicações negativas da atividade turística podem ser visivelmente observadas no Parque Municipal de Tupancy. Este parque cobre uma área de 21 hectares e é uma Unidade de Conservação criada pelo município de Arroio do Sal em 1996, com o objetivo de proteger os 
recursos naturais característicos da costa do RS e da mata atlântica, em especial dunas, lagoas interiores, banhados, mata de restinga bem como a flora e fauna associados a esse ambiente.

O parque, segundo informações obtidas durante a visita (no dia 19 de Maio de 2009), recebe na época baixa, cerca de 200 visitantes por dia e, na temporada alta, ela atinge os 500 visitantes (explicada principalmente pela elevada concentração de visitantes nos meses de verão). Esse número elevado de visitantes (mesmo na época baixa) tem destruído as trilhas e as dunas (foto 2). É certo que esse problema também pode estar associado a falta de vedação do parque. Contudo, esse número de visitantes é muito alto para a capacidade de carga do local, pois encontra-se numa área de ecossistema frágil.

Foto 2: Destruicão de trilhas e dunas no Parque de Tupancy

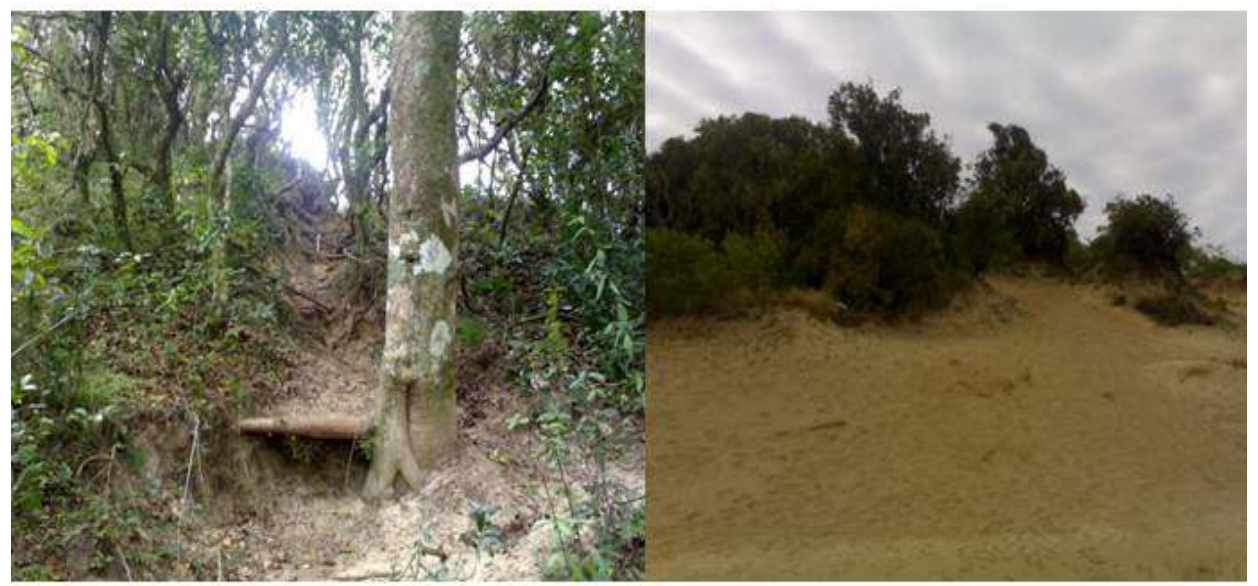

Fonte: Matos (19/05/2009)

\section{Turismo e gestão da zona costeira}

A partir dos anos de 1950 o litoral de muitos países, incluindo o norte do RS, foi ocupado por um crescente número de habitantes e veranistas, acelerando o processo de urbanização, que atingiu patamares nunca antes vistos e que teve implicações negativas no ambiente costeiro. Este processo está, principalmente, associado a criação de portos industriais e ao desenvolvimento do turismo de massas.

O turismo de massa, o balneário sobretudo, foi impulsionado pelo crescimento econômico e pelo progresso dos meios de transporte. Este tipo de turismo acelerou o processo de urbanização do litoral, encontrando em contra pé os planejadores que ficaram "mutilados" no tempo e, em alguns casos, adotando estratégias coniventes com a produção da mais-valia capitalista, abrindo as portas para a especulação imobiliária.

A intensa urbanização que vai afetar a zona costeira, associada a atividade turística provoca a transformação das sociedades locais, modifica o uso do espaço, põe em perigo os 
ecossistemas naturais como as dunas, a vegetação nativa, as lagoas e lagunas e agrava os conflitos entre os grupos sociais (CASTRO A. e MORALES C., 2006).

É preciso que se planeje o desenvolvimento da atividade turística, pois esta muitas vezes está preocupada com a produção da mais-valia, sendo neste âmbito, uma atividade menos preocupada com a conservação do ambiente (a longo prazo), mas sim com o aumento de lucros (a curto prazo).

Segundo Castro A. e Morales C. (2006), o ordenamento do território é um processo intelectual no qual se desenha uma ferramenta de intervenção de caráter técnico e instrumental (planejamento) que facilita a execução de uma série de ações de natureza executiva e política (gestão).

No geral, o planejamento e a gestão do território, neste caso da zona costeira, envolve vários níveis de participação, desde as comunidades locais que devem participar ativamente; como também o do nível técnico que se encarregará de formular parecer técnico sobre as caraterísticas da zona e as prováveis soluções ou medidas adequadas do seu uso. Mais acima está o nível político, que através de políticas públicas pode aprovar o parecer técnico, criando condições para a implementação do último nível, o de gestão.

A lógica de produção capitalista, que caracteriza o mundo urbano de hoje, vem se impondo como uma nova forma de produção do espaço urbano, e isso se reflete na homogeneização do padrão de ocupação do litoral norte do RS. Desde o município de Cidreira até ao município de Torres, observa-se a ocupação da orla por habitações de luxo ou habitações construídas para indivíduos com um poder aquisitivo, contrastando com as habitações precárias (que podem ser vistas um pouco mais para o interior).

Esta forma de produção do espaço do litoral, que agride com o ambiente costeiro, é de certa forma, fomentada pelos planos de urbanização existentes que, se o combatem, apenas o fazem no papel, pois parte da orla esta privatizada. A construção de habitações (os condomínios fechados e habitações individuais) é feita, em vários casos, sem respeitar as condições ambientais prevalecentes no local, daí que se verifica a destruição das dunas frontais (que como foi dito anteriormente, se verificam nesta faixa do litoral), lagunas, campos, banhados, balneários, áreas úmidas e a vegetação nativa.

Os processos destrutivos são mais intensos nos meses de verão, quando o número de habitantes cresce dez vezes mais, o que vai impor maior pressão sobre o ecossistema. As praias tornam-se espaços de deposição de dejetos, lixo e ainda em parques de estacionamento diurno. 
Esta forma de produção do espaço no veraneio parece animar as autoridades municipais que pouco fazem para evitar os impactos do "efeito veraneio", pois as infraestruturas existentes não são suficientes para responder a grande demanda e, a construção de segunda residência cresce a ritmos significativos.

As características das praias do litoral norte são totalmente expostas, observando-se de sul a norte, uma urbanização em processo e uma já consolidada. Isto implica ambientes que se encontram sujeitos a alta energia de ondas, ventos e correntes. Estas características, associadas a uma ocupação anárquica da orla, principalmente por habitações de segunda residência, e em áreas de ambientes frágeis, criam condições para a degradação do ambiente costeiro.

É certo que a erosão costeira pode ser provocada por processos naturais e por aqueles cuja origem não está ligada a escala local, como por exemplo as mudanças climáticas que parecem estar a ter um impacto no aumento do nível médio das águas do mar. Porém, também é verdade, que o homem, com as suas diferentes atividades desenvolvidas na zona costeira, com destaque para o turismo de massas, principalmente o de veraneio, vem tornando mais vulnerável esta área, acelerando o processo de destruição do ambiente costeiro. Isto, de certa forma, se manifesta na destruição das dunas, tanto pelo seu uso como matéria-prima, como também na sua destruição para a construção de habitações voltadas para atender o lazer e ao turismo.

Gerir o litoral norte gaúcho significa introduzir ferramentas/instrumentos adequados para evitar usos do solo que sejam conflitantes com a conservação deste ambiente, significa também um comprometimento com o desenvolvimento social e ambiental. Gerir esta faixa não significa que se deve banir o desenvolvimento da atividade turística, mas sim que esta deve ser enquadrada dentro de um turismo sustentável.

As características desta área imperam por uma gestão mais eficiente, pois se está perante uma área de preservação, constituída por ecossistemas raros e frágeis. Isto indica que, ao mantiver-se o atual ritmo do uso do solo, sem um plano de gestão integrado, perder-se-á um ecossistema raro. A perca desse ecossistema poderá, de certa forma, ter impactos negativos na atividade turística, visto que o turismo é uma atividade que depende principalmente da qualidade dos seus atrativos.

\section{Considerações finais}

A zona costeira é uma área de atração e concentração populacional e de várias atividades que, de certa forma, exercem pressão sobre ela. Uma dessas atividades é a 
exploração turística, que por sinal, foi em grande parte, responsável pelo desenvolvimento de assentamentos urbanos no litoral norte do Rio Grande do Sul.

O processo de desenvolvimento de assentamentos urbanos nessa área esteve relacionado com o "efeito veranista" e a construção de uma segunda residência, que caracterizou parte dos municípios dessa região. A construção de segunda habitação e o elevado número de visitantes que para esta área se deslocam nos meses de verão impõem maior pressão sobre os ecossistemas da área.

Essa pressão é mais preocupante quando se sabe que se está diante de um ecossistema frágil e raro e que faz parte de uma área de preservação. Contudo, a realidade parece não ter em conta essas frágeis características pois, o número de habitações de segunda residência vai crescendo e o verão vai abrindo, de uma forma descontrolada, as portas ao turismo de massa. Para além disso, o cenário torna-se mais preocupante dada a insuficiência de infra-estruturas de saneamento para dar vazão, não só aos residentes fixos, como também ao elevado número de veranistas.

Este cenário impõe a necessidade de se pensar num desenvolvimento sustentável da região. Esse desenvolvimento passa por um planejamento e gestão da zona costeira, de modo a evitar-se a degradação do mesmo e a consequente deterioração da qualidade de vida.

\section{Bibliografia consultada}

ALMEIDA, Luís E. S. B. et al. "Estimativas da Capacidade de Transporte de Sedimentos a partir de Dados de Ondas". In: MUEHE, Dieter (org.). Erosão e Progradação do Litoral Brasileiro. Brasília: MMA, 2006, p. 455-459.

BRASIL. Documento Síntese do I Simpósio Nacional sobre Erosão Costeira. Brasil: MMA, 2008.

CALLIARI, L. et al. "Classificação Geomorfológica”. In: MUEHE, Dieter (org.). Erosão e Progradação do Litoral Brasileiro. Brasília: MMA, 2006. p. 438-445

CASTRO A., Consuelo e MORALES C., Estaban. La Zona Costera: medio natural y ordenación integrada. Santiago de Chile: 2006. (Serie GEOlibros).

CNADS, Reflexão Sobre o Desenvolvimento Sustentável da Zona Costeira. 2001. 
VASCONCELOS, F. P. e CORIOLANO, L. N. T. “Impacto Sócio-Ambientais no Litoral: um foco no turismo e na gestão integrada da zona costeira no Estado de Ceará/Brasil”. In: Revista da Gestão Costeira Integrada. 8(2): 259-275. 2008.

FEPAM. Diretrizes Ambientais para o Desenvolvimento dos Municípios do Litoral Norte. Caderno de Planejamento e Gestão Ambiental no. 1. 2000.

FUJIMOTO, Nina S. V. M. Et al. "Litoral norte do estado do Rio Grande do Sul: indicadores socioeconômicos e principais problemas ambientais". In: Desenvolvimento e Meio Ambiente. n. 13. Editora UFPR, 2006, p. 99-124.

GOMES, Fernando V. Bases para a Estratégia de Gestão Integrada da Zona Costeira Nacional - projeto de relatório de grupo de trabalho. 2006.

HARVEY, David. A Justiça Social e a Cidade. São Paulo: Editora Hucitec. 1980.

LEFEBVRE, Henri. A Revolução Urbana. Belo Horizonte: Ed. UFMG. 1999.

NAKANO, Kazuo (coord.). Projeto Orla: Implementação em Territórios com Urbanização Consolidada. São Paulo: Instituto Plis; Brasília: Ministério do Planejamento e Gestão, 2006.

PROJETO ORLA: Fundamentos para Gestão Integrada. MMA/SQA. Brasília: MP/SPU, 2002.

SOARES, Marcelo. Impactos do turismo: os efeitos do ecoturismo em unidades de conservação. (s/d)

STROHAECKER Tânia M. et al. "Caracterização do uso e ocupação do solo nos municípios do litoral norte do estado do Rio Grande do Sul”. In: Desenvolvimento e Meio Ambiente. $n$. 13. Editora UFPR. 2006. p.75-98.

TOMAZELLI, L. J. \& VILLWOCK, J. A. “O Cenozóico Costeiro do Rio Grande do Sul”. In: HOLZ, M \& DE ROS, L. F. Geologia do Rio Grande do Sul. 2000. p. 375-406. 
VILLWOCK, J. A. “A Costa Brasileira: Geologia e Evolução”. In: Notas Técnicas 7. Porto Alegre: 1994. p. 38-49.

Sites visitados

http://www.arroiodosal.rs.gov.br/index.php?secao $=$ secao\&mostraconteudo=38 (último acesso 20 de Julho de 2009)

http://www.pmcc.com.br/index.php (último acesso 20 de Julho de 2009)

http://www.xangrila.rs.gov.br/ (último acesso 20 de Julho de 2009)

Http://www.ibge.org.br (último acesso 20 de Julho de 2009) 